\title{
Fetomaternal trauma in instrumental deliveries - a retrospective comparative study
}

\author{
Nitya R, Veena KS, R Rajeswari \\ Corresponding author: Dr. Veena KS, Associate Professor, Department of Obstetrics and \\ Gynecology, Sri ManakulaVinayagar Medical College and Hospital, Madagadipet, Pondicherry, \\ India; Email : ssykid2003@yahoo.co.uk
}

Distributed under Attribution-Non Commercial - Share Alike 4.0 International (CC BY-NC-SA 4.0)

\begin{abstract}
Objective: This study was undertaken to compare the fetomaternal trauma in forceps and vacuum deliveries. Methods: 103 forceps and 103 vacuum deliveries were considered in this retrospective study. Maternal outcome is assessed in terms of episiotomy extension, vaginal tears, cervical tears, exploration and repair under anesthesia, blood transfusion, vulval hematoma, puerperal pyrexia, and maternal mortality. Fetal outcome is assessed in terms of Apgar score, respiratory distress, birth asphyxia, meconium aspiration syndrome (MAS), necrotizing enterocolitis, hypoxic ischemic encephalopathy (HIE), hyperbilirubinemia, infection, duration of neonatal intensive unit (NICU) stay, birth injuries and infant mortality. Results: $85 \%$ of instrumental deliveries were conducted by consultants and $15 \%$ by residents. Decision to delivery interval was significantly lower in forceps compare to vacuum deliveries. Episiotomy extension and vaginal tears were significantly higher in forceps compare to vacuum. There was no significant difference in cervical tears, exploration and repair under anesthesia, blood transfusion, puerperal pyrexia, sepsis and maternal mortality. Apgar score, respiratory distress, birth asphyxia, MAS, necrotizing enterocolitis, HIE, hyperbilirubinemia, infection, duration of NICU stay and infant mortality was not significant between 2 groups. Conclusions: Vacuum delivery is associated with less maternal trauma compare to forceps delivery with no difference in neonatal outcome. Skill training for instrumental deliveries with modern education tools, simulators and hands on training for residents is need of the hour to achieve maternal and neonatal safety. Reasonable judgment in choosing cases along with skilled operators can reduce unwarranted caesareans in second stage.
\end{abstract}

Keywords: Maternal outcome, neonatal outcome, birth asphyxia, episiotomy extension, perineal tear.

Instrumental delivery is safe option for practicing modern obstetrics in second stage of labor. It is an essential skill for practicing obstetrician to reduce maternal and neonatal morbidity in second stage. Complications of delivery and obstructed labor accounted for $9.6 \%$ of all maternal deaths worldwide ${ }^{1}$. World has seen decreasing trend in instrumental deliveries with the rise of caesarean section rate. Data from $\mathrm{UK}^{2}$ stated that, the rate of instrumental deliveries are $10 \%$ which has been constant since several years with preference to vacuum delivery. Instrumental deliveries have key role in reducing maternal and fetal morbidity but compared to developed countries it is underused in developing world. The reasons for decreasing trend are fear of litigation, lack of skill training, availability of resources and fear of complications. Hence this study was undertaken to compare injuries associated with instrumental deliveries in the developing countries.

\section{Materials and methods}

This observational retrospective study was conducted at tertiary care maternity hospital, Pondicherry between January 2017 to June 2018 for a period of 18 months. Details of patients who had instrumental deliveries were collected from birth register. Consecutive 103 forceps and 103 vacuum delivery patients who fulfilled inclusion criteria were

Received: $5^{\text {th }}$ July 2020, Peer review completed: $17^{\text {th }}$ August 2020, Accepted: $7^{\text {th }}$ September 2020.

Nitya R, Veena KS, Rajeswari R. Fetomaternal trauma in instrumental deliveries - a retrospective comparative study. The New Indian Journal of OBGYN. 2022; 8(2): 251 - 56. 
considered for study. Case sheets were collected from medical record section and scrutinized for demographic characteristic, parity, gestational age, medical and obstetrical complications, indications for instrumental delivery, fetal and neonatal outcome following delivery. Malpresentation, gestational age $<36$ weeks, fetal head station-above +1 , dead baby, cervical dilatation $<10 \mathrm{cms}$, failed instrumental delivery, sequential use of instruments for delivery, multiple pregnancy and previous lower segment caesarean section (LSCS) cases excluded from study.

Metal and silastic cups were used in vacuum delivery. Negative pressure applied up to $0.6 \mathrm{~kg} / \mathrm{cm}^{2}$. Mid cavity forceps with or without axis traction device and outlet forceps were used in forceps delivery.

Maternal outcome was assessed in terms of episiotomy extension, vaginal tears, cervical tears, exploration and repair under anesthesia, blood transfusion, vulvar hematoma, puerperal pyrexia, urinary retention, sepsis, neuropraxia and maternal mortality. Fetal outcome was assessed in terms of Apgar score, respiratory distress, birth asphyxia, meconium aspiration syndrome, necrotizing enterocolitis, hypoxic ischemic encephalopathy, hyperbilirubinemia, infection, duration of stay at NICU, birth injuries and infant mortality. The collected was analyzed and tabulated.

The quantitative variables between the two groups were compared using parametric ( $\mathrm{T}$-independent test) and nonparametric tests (Mann Whitney $U$ test), wherever appropriate. As for the qualitative variables, the significance of their occurrence in the two groups was compared in terms of proportions. Proportions wherever necessary were compared using Chi square or Fisher's test which ever was appropriate. In all comparisons, a $\mathrm{P}$-value of $<0.05$ was considered to be statistically significant.

\section{Results}

The total number of deliveries for 1 year was 19440 . Total number of LSCS were 4471(22.99\%) and instrumental deliveries were $748(3.8 \%)$ among which 481(64.3\%) were forceps deliveries and 267(35.7\%) were vacuum deliveries. $85 \%$ of instrumental deliveries were conducted by consultants and $15 \%$ of instrumental deliveries were conducted by residents.

Demographic profile of the patients has been described in table 1. There was no significant difference among two groups of patients in terms of height, weight, age parity and gestational age.

The proportion of cases with different positions among the forceps and vacuum group are shown in table 2. It was observed that the proportion of cases with position "left occipito-anterior" was significantly higher in the forceps group when compared to the same in vacuum group. It was observed that the proportion of cases with position "left occipito-transverse" was found higher in the vacuum group. The proportion of cases with position "posterior" was almost the same in both the groups. Proportion of cases with station of +3 was significantly higher in the forceps group when compared to the same in the vacuum group $(p=0.0002)$.

Table 1: Demographic characteristics

\begin{tabular}{lllll}
\hline \multicolumn{2}{l}{ Demographic characteristics } & $\begin{array}{l}\text { Forceps } \\
\text { delivery }\end{array}$ & $\begin{array}{l}\text { Vacuum } \\
\text { delivery }\end{array}$ & $\begin{array}{l}\text { P } \\
\text { value }\end{array}$ \\
\hline $\begin{array}{l}\text { Maternal age in years } \\
\text { (Mean } \pm \text { SD) }\end{array}$ & $23 \pm 4.1$ & $24 \pm 3.9$ & NS \\
\hline Height in cm & $135-144$ & $4(3.88)$ & $1(0.97)$ & NS \\
& $145-154$ & $89(86.4)$ & $87(84.46)$ & NS \\
& $155-166$ & $10(9.70)$ & $15(14.56)$ & NS \\
\hline Parity & Primigravida & $88(85.44)$ & $77(74.76)$ & $\mathrm{NS}$ \\
& Multi gravid & $15(14.56)$ & $26(25.24)$ & $\mathrm{NS}$ \\
\hline Period of & 36 & $1(0.98)$ & $2(1.95)$ & $\mathrm{NS}$ \\
gestation & 37 & $2(1.95)$ & $1(0.98)$ & $\mathrm{NS}$ \\
(Week) & $39-40$ & $100(97.09)$ & $95(92.24)$ & $\mathrm{NS}$ \\
\hline NS - Nonsignificant & & &
\end{tabular}

Indication for instrumental delivery is described in table 3. It is observed that for all the possible indications listed, the proportion of cases with short rotation was significantly higher among vacuum group ( $\mathrm{p}$ value $<0.05$ ). Forceps method was common mode of delivery in the indications like fetal distress and failure of maternal power compared to vacuum group.

Table 2: Station and position of head in forceps and vacuum groups

\begin{tabular}{llll}
\hline Position & $\begin{array}{l}\text { Forceps } \\
\mathbf{N}(\%)\end{array}$ & $\begin{array}{l}\text { Vacuum } \\
\mathbf{N}(\%)\end{array}$ & $\begin{array}{l}\text { P } \\
\text { value }\end{array}$ \\
\hline Left occipito-anterior & $98(95.15)$ & $61(59.23)$ & $<0.05$ \\
Left occipito-transverse & $1(0.98)$ & $38(36.9)$ & $<0.05$ \\
Occipito-posterior & $4(3.89)$ & $4(3.89)$ & $\mathrm{NS}$ \\
\hline Station & & & \\
+1 & $5(4.86)$ & $11(10.68)$ & $\mathrm{NS}$ \\
+2 & $77(74.76)$ & $88(85.44)$ & $\mathrm{NS}$ \\
+3 & $21(20.39)$ & $4(3.89)$ & $\mathrm{P}<0.05$ \\
\hline
\end{tabular}

The color of liquor among the cases in the two groups is shown in table 4 . There was no association between color of liquor and the type of delivery method used $(\mathrm{p}>0.05)$.

$96(93.2 \%)$ of forceps group and $83(80.5 \%)$ of vacuum group had delivery with 3 or less pulls. $7(6.8 \%)$ among forceps group and 20(19.4\%) of vacuum group had delivery with $>3$ pulls. Maximum 5 pulls were used for instrumental delivery. The difference was statistically significant between 2 groups. The decision-to-delivery interval was $10 \pm 5.4 \mathrm{~min}$ for forceps delivery compare to $17 \pm 6.2$ minutes for vacuum deliveries. $\mathrm{P}$ value was $<0.05$ which is statistically significant.

Neonatal outcome is described in table 5. There was no statistical difference in birth weight between the groups. There was no statistical significant difference between two 
The New Indian Journal of OBGYN. 2021 (January-June);8(2)

groups when duration of NICU stay is concerned (chi square $0.05, \mathrm{P}=0.77$ ). The mean of Apgar score at birth for forceps and vacuum delivery was 7.1 and 7.2 respectively. There was no statistical difference in Apgar score at birth in either the group.

\begin{tabular}{llll}
\multicolumn{4}{l}{ Table 3: Indications for instrumental delivery } \\
\hline Maternal indication & Forceps & $\begin{array}{l}\text { Vacuum } \\
\mathbf{N}(\%)\end{array}$ & $\begin{array}{l}\mathbf{P} \\
\text { value }\end{array}$ \\
\hline Anemia in failure & $2(1.94)$ & $2(1.94)$ & NS \\
Cardiac disease & $1(0.97)$ & $2(1.94)$ & NS \\
Severe PIH/ Eclampsia & $3(2.91)$ & $1(0.97)$ & NS \\
\hline
\end{tabular}

\begin{tabular}{llll}
\hline Fetal indication & & & \\
Fetal distress & $18(17.48)$ & $7(6.8)$ & $<0.05$ \\
Cord prolapse & $1(0.97)$ & $0(0)$ & NS \\
\hline Obstetrical indication & & & \\
Failure of maternal power & $46(44.66)$ & $16(15.53)$ & $<0.05$ \\
$\begin{array}{l}\text { Prolonged } 2^{\text {nd }} \text { stage } \\
\text { Short of rotation }\end{array}$ & $30(29.12)$ & $22(21.36)$ & NS \\
\hline
\end{tabular}

\begin{tabular}{llll}
$\begin{array}{lll}\text { Table 4: Color of liquor } \\
\text { Meconium } \\
\text { status }\end{array}$ & $\begin{array}{l}\text { Forceps } \\
\text { N(\%) }\end{array}$ & $\begin{array}{l}\text { Vacuum } \\
\text { N(\%) }\end{array}$ & $\begin{array}{l}\text { P } \\
\text { value }\end{array}$ \\
\hline Clear & $88(85.44)$ & $78(75.73)$ & NS \\
Thin & $7(6.8)$ & $12(11.66)$ & NS \\
Thick & $8(7.77)$ & $13(12.63)$ & NS \\
\hline
\end{tabular}

Table 5: Neonatal outcome

\begin{tabular}{llll}
\hline Birth weight (Kg) & $\begin{array}{l}\text { Forceps } \\
\mathbf{N}(\%)\end{array}$ & $\begin{array}{l}\text { Vacuum } \\
\mathbf{N}(\%)\end{array}$ & $\begin{array}{l}\mathbf{P} \\
\text { value }\end{array}$ \\
\hline$<2$ & $3(2.92)$ & $5(4.86)$ & \\
$2-2.5$ & $24(23.31)$ & $26(25.25)$ & \\
$2.6-3$ & $47(45.64)$ & $47(45.64)$ & \\
$3.1-3.5$ & $26(25.25)$ & $22(21.36)$ & \\
$>3.5$ & $3(2.92)$ & $3(2.92)$ & \\
Mean \pm SD & $2.92 \pm 0.04$ & $3 \pm 0.04$ & $\mathrm{NS}$ \\
\hline Apgar score & & & \\
$<3$ & $2(1.95)$ & $3(2.92)$ & $\mathrm{NS}$ \\
$3-6$ & $23(22.34)$ & $18(17.48)$ & $\mathrm{NS}$ \\
$>6$ & $78(75.73)$ & $82(79.62)$ & $\mathrm{NS}$ \\
\hline NICU stay (in days) & & & \\
$<1$ & $43(41.75)$ & $47(45.64)$ & $\mathrm{NS}$ \\
$1-5$ & $52(50.49)$ & $50(48.55)$ & \\
$>5$ & $8(7.77)$ & $6(5.83)$ & \\
\hline
\end{tabular}

The Maternal outcome is presented in table 6 . Episiotomy extension and vaginal tears were significantly higher in forceps compare to vacuum delivery. Infection was common in forceps but difference was not significant. We did not find any urinary retention and neurological injuries.

Birth asphyxia was commonly (25\%) seen in vacuum deliveries but meconium aspiration syndrome (15.5\%) was commonly seen in forceps deliveries but the difference was not statistically significant. Eye injuries which included 4 subconjunctival hemorrhage and 2 corneal tears were among forceps group with no eye injuries in vacuum group, difference was statistically significant. There was no cephalhematoma in forceps group compared to vacuum with 8 cases and statistical difference was significant.

\begin{tabular}{|c|c|c|c|}
\hline Maternal injuries & $\begin{array}{l}\text { Forceps } \\
\mathbf{N}(\%)\end{array}$ & $\begin{array}{l}\text { Vacuum } \\
\mathrm{N}(\%)\end{array}$ & $\begin{array}{l}P \\
\text { value }\end{array}$ \\
\hline Episiotomy extension & $18(17.48)$ & $1(1.0)$ & $<0.05$ \\
\hline Vaginal tears & $15(14.55)$ & $4(3.9)$ & $<0.05$ \\
\hline Cervical tears & $2(1.9)$ & $1(1.0)$ & NS \\
\hline $3^{\text {rd }}$ degree perineal tear & $1(.97)$ & $2(1.9)$ & NS \\
\hline Complete perineal tear & $1(.97)$ & $2(1.9)$ & NS \\
\hline \multicolumn{4}{|l|}{ Other complications } \\
\hline \multicolumn{4}{|l|}{ Exploration and repair under } \\
\hline Blood transfusion & $3(2.9)$ & $4(3.9)$ & NS \\
\hline Vulval hematoma & $0(0.0)$ & $1(0.97)$ & NS \\
\hline Puerperal infection & $7(6.79)$ & $3(2.9)$ & NS \\
\hline Postpartum hemorrhage & $7(6.79)$ & $4(3.9)$ & NS \\
\hline \multicolumn{4}{|c|}{ Table 7: Perinatal outcome among the forceps and vacuum groups } \\
\hline $\begin{array}{l}\text { Perinatal } \\
\text { outcome }\end{array}$ & $\begin{array}{l}\text { Forceps } \\
\text { N(\%) }\end{array}$ & $\begin{array}{l}\text { Vacuum } \\
\mathrm{N}(\%)\end{array}$ & $\begin{array}{l}\mathbf{P} \\
\text { value }\end{array}$ \\
\hline Respiratory distress & $3(2.9)$ & $6(5.3)$ & NS \\
\hline Birth asphyxia & $16(15.5)$ & $26(25.2)$ & NS \\
\hline Meconium aspiration syndrome & $16(15.5)$ & $8(7.8)$ & NS \\
\hline Hypoxic ischemic encephalopathy & $2(1.9)$ & $3(2.9)$ & NS \\
\hline Hyperbilirubinemia & $1(0.97)$ & $4(3.9)$ & NS \\
\hline Infection & $0(0.0)$ & $1(0.97)$ & NS \\
\hline Brachial pluxes injury & $1(0.97)$ & $0(0.0)$ & NS \\
\hline Eye injuries & $6(5.8)$ & $0(0.00)$ & $<0.05$ \\
\hline Mortality & $4(3.9)$ & $3(2.9)$ & NS \\
\hline Cephalhematoma & $0(0.0)$ & $8(7.8)$ & $<0.05$ \\
\hline NICU stay $>5$ days & $8(7.77)$ & $6(5.83)$ & NS \\
\hline
\end{tabular}

\section{Discussion}

Instrumental deliveries are safe obstetric skills when chosen the cases appropriately. In our study the rate of instrumental deliveries was $3.8 \%$ which is much lower compare to other studies ${ }^{3,4}$ from India. Data from subSaharan Africa has stated much lower instrumental deliveries $(<1 \%)$. $40 \%$ of sub-Saharan African countries and 30\% Asian countries, never used or taught vacuum extraction ${ }^{5}$. In the US, instrumental delivery reduced from $9.01 \%$ of all deliveries in 1992 to $3.30 \%$ in $2013^{6}$. Replacement of high and rotational forceps deliveries by caesarean deliveries, unavailability of instruments, less usage of obstetric analgesia and poor quality training in developing countries may be the reasons for this trend. In our study, $85 \%$ instrumental deliveries were conducted by specialist and $15 \%$ by residents. Only prophylactic instrumental vaginal deliveries were given to residents. Many young doctors complete their post-graduation with minimal hands on experience for instrumental deliveries. Sentilhes L, et al ${ }^{7}$ observed that operative vaginal delivery managed by an obstetric resident under supervision was not associated with a greater rate of severe maternal and neonatal morbidity. 
Obstetricians need to be competent in conducting instrumental deliveries in certain inevitable situations. Dr. Nicola Perone ${ }^{8}$ devised high-fidelity simulator which makes it easier for young doctors to become proficient. Simulator training along with hands on experience may help residents to become self-confident and gives them the ability to teach their juniors.

UK data suggest that $10-15 \%{ }^{9}$ of all deliveries are instrumental deliveries with preference to vacuum. In our study forceps was preferred instrument with ratio being 1.8 contrary to other studies ${ }^{3,10}$. Though vacuum is having advantage of technical simplicity and less maternal trauma, non availability of modern cups and complex maintenance may be the reasons for this trend in our hospital. Metal cups were frequently used and kiwi cups were not available at the time of study.

Choosing the right case for instrumental delivery influences the outcome of delivery. Forceps were the preferred instrument in woman with occipito - anterior position and station at +3 but vacuum was preferred in occipito-transverse position. As the rotational forceps deliveries has seen downward trend vacuum is being used wherever rotation is required. The reasons for this trend may be ease of application of vacuum in malrotated head compare to forceps.

In our study, forceps were preferred in cases of fetal distress and failure of maternal efforts in accordance with other studies ${ }^{3,11}$ but vacuum is preferred in malrotation. We achieved quicker 'decision to delivery interval' in forceps compared to vacuum $(10 \pm 5.4$ vs. $17 \pm 6.2$ minutes $)$ which was similar to other studies ${ }^{12}$. This finding favors preference for forceps in fetal distress.

Overall maternal trauma in instrumental deliveries accounts for $13.5 \%$ in our study. Occurrence of genital trauma in forceps deliver was high (18.4\%) compared to vacuum $(8.7 \%)$. Routine episiotomy with operative vaginal delivery is not recommended because of poor healing and prolonged discomfort ${ }^{13}$. Vaginal tears and extension of episiotomy among forceps was significantly high comparatively all though episiotomy was given for all instrumental deliveries. Vacuum seems to be safe for the mother compared to forceps in our study. This finding is in accordance with cochrane database ${ }^{14}$ review study. Retrospective cross-sectional study conducted in Ethiopia ${ }^{15}$ found that mothers who had forceps delivery were 3.4 times more likely to develop maternal complication than vacuum delivery. Cochrane database ${ }^{14}$ review showed that third and fourth degree perineal tears occur more frequently in forceps compared to vacuum. Contrary to other studies ${ }^{3,16}$ our study did not show any difference in occurrence of sphincter injuries in forceps as compared to vacuum. Although there was increased maternal trauma in forceps wound infection rates were comparable. José A et al ${ }^{17}$ studied levator ani muscle injury in operative vaginal delivery with Malmström vacuum or Kielland forceps and they did not find any difference between groups. Change in the profile of patients, anemia, obesity and increasing trends in diabetes complicating pregnancy have multiple consequences in both maternal and fetal health. Hence there is need for further studies.

Birth injuries associated with difficult operative deliveries are one of the common litigations in obstetrics practice. Our study showed higher incidence of cephalhematoma in vacuum group compare to forceps which was similar to other studies ${ }^{3,11,18}$. Use of metal cups increase the chance of cephalhematoma compared to silastic cups. In our hospital metal cups were used more often compared to silastic cups. We did not find severe complications like hypotension and anemia in cephalhematoma cases. Difficult vacuum deliveries, such as occipito-posterior or transverse position and fetal mid station, predispose to increased scalp injuries $^{19}$. This can be minimized by correct assessment of position, right application of the cup, prevention of slippage of cup and traction in appropriate direction. Subconjunctival hemorrhage and corneal tears were more frequently seen in forceps group however cases were managed conservatively without any surgical intervention. Prapas et al 20 demonstrated low Apgar scores at 1 minute in forceps group compared to vacuum however neonatal trauma did not differ. In our study neonatal outcome did not differ in terms of Apgar scores, birth asphyxia, respiratory distress, prolonged NICU stay and sepsis.

Limitations: This is a cross-sectional study hence it was not possible to establish causal relationship between variables and the mode of delivery. Being retrospective in nature important parameters like body mass index of the mother, hemoglobin levels, and diabetic status were not addressed in this study. Sequential use of instrument and failed instrumentation were not included in the study. The study was conducted in a single hospital; the results might not be a representative of other institutions.

\section{Conclusions}

Vacuum delivery is associated with less maternal trauma compare to forceps delivery with no difference in neonatal outcome. Selection of cases and skill of the operator determined fetomaternal outcome of instrumental delivery. 
The New Indian Journal of OBGYN. 2021 (January-June);8(2)

Reduced incidence of instrumental deliveries in developing world need to be addressed in order to prevent obstructed labor in second stage of labor. Skill training for instrumental deliveries with modern education tools, simulators and hands on training for residents is need of the hour to achieve maternal and neonatal safety. Reasonable judgment in choosing cases along with skilled operators can reduce unwarranted caesarean sections in second stage.

\section{Conflict of interest: None. Disclaimer: Nil.}

\section{References}

1. Lale S, Doris C, Alison G, Özge T, Ann-Beth M, Jane D, et al. Global causes of maternal death: A WHO systematic analysis. Lancet Glob Health. 2014 June; 2: e323-33

2. Merriam AA, Ananth CV, Wright JD, Siddiq Z, D'Alton ME, Friedmana AM. Trends in operative vaginal delivery, 2005-2013 a population-based study. BJOG: Int J Obstet Gy. 2017; 124(9): 1365-72.

3. Chaudhari P, Bansal N, Gupta V, Tandon A, Chaudhry A. A comparative study of feto-maternal outcome in instrumental vaginal delivery at tertiary health level hospital in Uttarakhand state. IntJ Reprod Contracept Obstet Gynecol. 2016; 5: 3294-9.

4. SnehaBD, Ramesh CC. Trends of instrumental deliveries at a tertiary care teaching hospital in Puducherry. Indian Journal Of Applied Research. 2015; 5(7): 513-5.

5. Bailey PE. The disappearing art of instrumental delivery: Time to reverse the trend. Int $\mathrm{J}$ Gynecol Obstet. 2005; 91:89-96.

6. Martin JA, Hamilton BE, Osterman MJ, Curtin SC, Matthews TJ. Births: final data for 2013. Natl Vital Stat Rep. 2015; 64:1-65.

7. Sentilhes L, Madar H, Ducarme G, Jean-François H, Aurélien M, Matthieu H. Outcomes of operative vaginal delivery managed byresidents under supervision and attending obstetricians: a prospective cross-sectional study. Am J Obstet Gynecol. 2019; 122(1): 59.e159.e15.

8. Nicola P. Advanced technology in obstetric education: a high-fidelity simulator for operative vaginal Delivery. J Perinat Med. 2019; 47(9): 932-40.

9. Royal College of Obstetricians and Gynecologists. Operative Vaginal delivery. Green-top Guidelines No 26. London: RCOG; 2020. Available at: https://www. rcog.org.uk/en/guidelines-research-services/ guidelines/gtg26/

10. Lurie S, Glezerman M, Sadan O. Maternal and neonatal effects of forceps versus vacuum operative vaginal delivery. Intern J Gynecol Obstetr. 2005; 89(3):293-4.

11. Singh A, Rathore P. A Comparative Study of FetoMaternal Outcome in Instrumental Vaginal Delivery. Journal of Obstetrics and Gynecology of India. 2011; 61(6): 663-6.

12. Okunwobi YS, Cooke I, Mackenzie IZ. Decision to delivery intervals for assisted vaginal vertex delivery. BJOG. 2000; 107: 467-71.

13. The American College of Obstetricians and Gynecologists. Practice Bulletin, Number - 154 Washington: ACOG; November 2015.

14. O'Mahony F, Hofmeyr GJ, Menon V. Choice of instruments for assisted vaginal delivery. Cochrane Database of Systematic Reviews. 2010; 11: CD005455.

15. Shimeles B, Dagne A, Simachew K, Simachew A. Maternal complication related to instrumental delivery at Felege Hiwot Specialized Hospital, Northwest Ethiopia:a retrospective cross-sectional study. BMC Res Notes. 2019; 12:482.

16. Eason E, Labrecque M, Marcoux S, Mondor M. Anal incontinence after childbirth. Canadian Med Assoc J. 2002; 166(3): 326-30.

17. Jose A, Garcia M, Ana FP, Bonomi Barby MJ, Laura C, Adriana A. A comparable rate of levator ani muscle injury in operative vaginal delivery (forceps and vacuum) according to the characteristics of the instrumentation. Acta Obstet Gynecol Scand. 2019; 98:729-36.

18. Shekhar S, Rana N, Jaswal R. A Prospective Randomized Study Comparing Maternal and Fetal Effects of Forceps Delivery and Vacuum Extraction. The Journal of Obstetrics and Gynecology of India. 2013; 63(2):116-9.

19. Stergios KD, Sabaratnam A. Head injuries after instrumental vaginal deliveries. Current Opinion in Obstetrics and Gynecology. 2006; 18:129-34.

20. Prapas N, Kalogiannidis I, Masoura S, Diaman E Makedos A, Drossou D, et al. Operative vaginal delivery in singleton term pregnancies: short term maternal and neonatal outcomes. Hippokratia. 2009; 13:41-5. 
The New Indian Journal of OBGYN. 2021 (January-June);8(2)

Nitya $\mathbf{R}^{1}$, Veena $\mathrm{KS}^{2}$, R Rajeswari ${ }^{3}$

${ }^{1}$ Assistant Professor, Department of Obstetrics and Gynecology, Sri Lakshmi narayana Medical College and Hospital, Pondicherry, India; ${ }^{2}$ Associate
Professor, Department of Obstetrics and Gynecology, Sri ManakulaVinayagar Medical College and Hospital, Madagadipet, Pondicherry, India; ${ }^{3} \mathrm{CMO}(\mathrm{SAG})$, Rajiv Gandhi Govt Maternity Hospital, Pondicherry, India. 